\title{
Activation of Methane on NiO Nanoparticles with Different Morphologies
}

\author{
Ruth L. Martins and Martin Schmal*,\# \\ Federal University of Rio de Janeiro, NUCAT-PEQ-COPPE, Bl G-128, Centro de Tecnologia, \\ 21945-970 Rio de Janeiro-RJ, Brazil
}

\begin{abstract}
Superfícies nanoestruturadas podem ser definidas como substratos tendo como principal característica dimensões na faixa de 1-100 nm. O recente interesse nestes sistemas é baseado no fato de que novas e interessantes propriedade (catalíticas, magnéticas, ferroelétricas, mecânicas, óticas e eletrônicas) são desenvolvidas como resultado da redução da dimensão destes substratos. Neste trabalho descreve-se a decomposição catalítica do metano em hidrogênio e nanofilamentos de carbono em catalisadores não suportados de Ni preparados por metodologias distintas. Catalisador de Ni suportado em zircônia foi usado para comparação dos resultados. Para os catalisadores não suportados, observou-se forte dependência da atividade do catalisador com o tamanho da partícula do óxido precursor e sua morfologia. Apesar de todos terem apresentado dimensões na faixa de nanopartículas, somente os preparados usando etileno glicol, NiEG, e rota hidrotérmica, NiHT, exibiram a mesma performance que o catalisador suportado (atividade e estabilidade), $25 \mathrm{NiZ}$. O catalisador sintetizado em presença de dimetilglioxima, NiDMG, foi o menos ativo e desativou com o tempo em operação.
\end{abstract}

Nanostructured surfaces can be defined as substrates in which the typical features have dimensions in the range of $1-100 \mathrm{~nm}$. The recent focus of interest in these systems is based on the fact that interesting novel properties (catalytic, magnetic, ferroelectric, mechanical, optical and electronic) are developed as a result of the dimension reductions of these substrates. This paper describes the catalytic methane decomposition into hydrogen and carbon nanofilaments on unsupported Ni catalysts prepared from different methodologies, with controlled particle size and morphologies. Ni catalyst supported on zirconia was also used for performance comparison. For the unsupported catalysts, it was observed strong dependency of catalyst activities with particle size of nickel oxide precursors and their morphologies. Although all of them presented crystallite sizes with nanometric dimensions, only those prepared with ethylene glycol, NiEG, and by hydrothermal condition, NiHT, exhibited the same performance as the supported catalyst (activity and stability), 25NiZ. Catalyst synthesized in the presence of dimethylglyoxime, NiDMG, was less active and deactivated with time on stream.

Keywords: $\mathrm{NiO}$, nanoparticles, $\mathrm{H}_{2}$ production, carbon nanofilaments

\section{Introduction}

There are many new challenges ahead in the field of heterogeneous catalysis in terms of the chemical process and reactions to be promoted by the use of nano catalysts. As an example, the conversion of methane, which is usually performed by different direct or indirectly routes, require specific catalysts. Non oxidative methane process is relevant for investigating the different possibilities of

*e-mail: schmal@peq.coppe.ufrj.br

"Present adress: Dept. Chem. Eng., University of São Paulo, 05424-970 São Paulo-SP, Brazil

In honor of Prof Roberto F. de Souza (passed away Oct. 2013) methane activation and posterior interaction between the molecules or intermediates and the surface of the catalyst and thus, for understanding the reaction mechanisms governing the formation of $\mathrm{C}-\mathrm{C}$ bonding, the reaction condition influencing the formation of these ligands, as well as, the product distribution, which are of fundamental interest, not only for the non-oxidative coupling but also on processes related to the methane transformation.

Martins et al. ${ }^{1}$ reported the role of different supports (silica, alumina and zirconia) on the non-oxidative conversion of methane on Pt loaded catalysts, with or without the presence of $\mathrm{MoO}_{3}$. Moya et al. ${ }^{2}$ studied the non-oxidative methane coupling on nanostructured 
supported palladium catalysts and Antje Ota et al. ${ }^{3}$ studied the particle size effect in methane activation over supported palladium nanoparticles. Moya et al..$^{4}$ studied the monodispersed and nanostructrured $\mathrm{Ni} / \mathrm{SiO}_{2}$ catalyst for the non-oxidative methane activation.

Also, direct cracking of methane on supported $\mathrm{Ni}$ catalyst were reported in the literature..$^{5-7}$

$$
\mathrm{CH}_{4} \rightarrow \mathrm{C}+2 \mathrm{H}_{2}, \Delta \mathrm{H}_{298^{\circ}}=75.6 \mathrm{~kJ} \mathrm{~mol}^{-1}
$$

This process is moderately endothermic, with little gain in energy needed per mol of $\mathrm{H}_{2}$ production and the reaction is thermodynamically favored at higher temperatures. The $\mathrm{H}_{2} / \mathrm{CH}_{4}$ is low during methane cracking with carbon structure formation. Direct cracking forms nanofilament carbons with graphite planes as precursor. On supported nickel catalysts, hydrocarbons are decomposed at the interface gas-metal followed by dissolution and carbon diffusion through the metal particles. These carbons then precipitate at the interface, dragging out the metallic particle of the support with the formation of carbon filaments, as observed by Aiello et al. ${ }^{8}$ for the $\mathrm{Ni} / \mathrm{SiO}_{2}$ and Alberton et al. ${ }^{9}$ for the $\mathrm{Ni} / \mathrm{Al}_{2} \mathrm{O}_{3}$ catalysts. Methane cracking for hydrogen production was studied over $\mathrm{Ni} / \mathrm{Ni}$ alloy catalysts supported on pure or $\mathrm{WO}_{3} / \mathrm{MoO}_{3^{-}}$modified zirconias by Martins et al.. ${ }^{10}$ On unsupported Ni nanoparticles there are formation of carbon nanotubes.

Metallic catalysts, in the catalysis concept, are usually prepared by the deposition of small nanometer-sized particles $(<20 \mathrm{~nm})$ of an active phase, a metal, finely dispersed on a cheaper high-surface-area support, commonly a porous oxide. The dispersion is used mainly to improve the surfaceto-volume ratio of the active phase. Additionally, this practice also leads to a better distribution of reaction heat, better poison resistance, and improve catalyst life by preventing metal sintering. Supported catalysts are prepared by impregnation of the porous solid with a precursor metal salt followed by oxidation and reduction pretreatments. However, that practice leads to the formation of nanoparticles with a wide range of sizes and shapes displaying a distribution of surface sites capable of promoting many different reactions. No molecular control on the nature of the active sites is expected, and only limited control on the selectivity of reactions can be achieved. Controlling the size of the nanoparticles used for catalysis can lead to huge changes in catalytic behavior. The importance of nanoparticles and nanostructure to the performance of catalysts has stimulated wide efforts to develop methods for their synthesis and characterization, making this area of study an integral part of nanoscience. ${ }^{11}$ Fortunately, metal nanoparticles can now be made with quite narrow size distributions by using, beside others, colloidal ${ }^{12}$ or dendrimer ${ }^{13}$ based chemistry. The morphology of these materials depends on the syntheses conditions, and has been described by different authors as nanotowers, nanocone, nanobottle, nanoflowers, nanoarrows, nanorod, nanowires and so on. The challenge is to disperse the colloidal nanoparticles on high-surface area supports and to activate them without losing the original size and shape distribution. As a matter of fact, the control of the morphology of the nanoparticles, perhaps, seems to be more important than monitoring the performance of catalysts by controlling the size of the nanoparticles of the active phase. It has been known that some catalytic processes are structure sensitive, meaning that their activity or selectivity changes significantly with the method used for the catalyst preparation.

In this work, we present methane activation on $\mathrm{Ni}$ nanoparticles with different morphologies synthesized by different methods for the methane activation and characterized before and after activation of methane.

\section{Experimental}

\section{Preparation of catalysts}

$\mathrm{Ni}$ catalysts with $25 \mathrm{wt} . \%$ of $\mathrm{NiO}$ were prepared by incipient wetness impregnation of $\mathrm{Ni}\left(\mathrm{NO}_{3}\right)_{2} \cdot 6 \mathrm{H}_{2} \mathrm{O}$, using as $\mathrm{ZrO}_{2}$ precursor the $\mathrm{Zr}(\mathrm{OH})_{4}$ (MEL Chemical). Usually zirconia, obtained by calcination of $\mathrm{Zr}(\mathrm{OH})_{4}$ at $923 \mathrm{~K}$, involves two phases: stable monoclinic zirconia $(\mathrm{M})$ and metastable tetragonal zirconia (T). The zirconia obtained by calcination of pure $\mathrm{Zr}(\mathrm{OH})_{4}$ at $923 \mathrm{~K}$ for $3 \mathrm{~h}$ is mostly monoclinic, while Ni modified zirconias (where Ni content is equal or greater than $20 \mathrm{wt} . \%$ ) are predominantly tetragonal in structure. ${ }^{10}$ After drying at $373 \mathrm{~K}$ for $24 \mathrm{~h}$, the catalyst was calcined in the presence of synthetic air at $923 \mathrm{~K}$ for $3 \mathrm{~h}$, at a ramping rate of $1 \mathrm{~K} \mathrm{~min}^{-1}$.

The $\mathrm{NiO}$ with controlled crystallite sizes were prepared by three different methods.

(i) Precipitation of nickel hydroxide with sodium carbonate precursor salts dissolved in ethylene glycol (EG) (NiEG) according to Li et al..$^{14} \mathrm{Ni}\left(\mathrm{NO}_{3}\right)_{2} \cdot 6 \mathrm{H}_{2} \mathrm{O}$ was dissolved in ethylene glycol ( $0.05 \mathrm{~mol}$ in $150 \mathrm{~mL}$ of $\mathrm{EG})$, heated gradually at $393 \mathrm{~K}$ under stirring and kept at this temperature for $30 \mathrm{~min}$, followed by drop wise addition of a solution of $500 \mathrm{~mL}$ of $0.2 \mathrm{~mol} \mathrm{~L}^{-1}$ of $\mathrm{Na}_{2} \mathrm{CO}_{3}$, aged for $1 \mathrm{~h}$ at $393 \mathrm{~K}$, filtered, washed with distilled-deionized water and then dried at $373 \mathrm{~K}$ for $16 \mathrm{~h}$. The resulting sample was calcined at $673 \mathrm{~K}$ for $4 \mathrm{~h}$ flowing synthetic air at $50 \mathrm{~mL} \mathrm{~min}^{-1}$.

(ii) Precipitation of nickel dimethylglyoxyme as precursor (NiDMG) according to Ni et al.: ${ }^{15} 3 \mathrm{~g}$ of $\mathrm{Ni}\left(\mathrm{NO}_{3}\right)_{2} \cdot 6 \mathrm{H}_{2} \mathrm{O}$ was dissolved in $650 \mathrm{~mL}$ of distilled- 
deionized water. A solution of $334 \mathrm{~mL}$ of ethanol containing $1 \%$ of dimethylglyoxyme was added dropwise to the solution with the formation of a red precursor of $\mathrm{Ni}(\mathrm{DMG})_{2}$. After centrifugation and washing with distilled-deionized water, the precipitated solid was dried at $373 \mathrm{~K}$ for $16 \mathrm{~h}$ and calcined at $673 \mathrm{~K}$ for $4 \mathrm{~h}$ under atmospheric air and heating rate of $3 \mathrm{~K} \mathrm{~min}^{-1}$.

(iii) $\mathrm{NiO}$ was obtained after hydrotreatment and calcination of $\beta-\mathrm{Ni}(\mathrm{OH})_{2}$ precursor (NiHT) according to Zhu et al.: $:^{16}$ about $1 \mathrm{mmol}$ of $\mathrm{Ni}\left(\mathrm{CH}_{3} \mathrm{COO}\right)_{2} \cdot 4 \mathrm{H}_{2} \mathrm{O}$ was dissolved in $5 \mathrm{~mL}$ distilled-deionized water followed by addition of $15 \mathrm{~mL}$ ethanol and $5 \mathrm{~mL}$ of $\mathrm{CO}\left(\mathrm{NH}_{2}\right)_{2}$, under strong stirring. Then, adding $2 \mathrm{~mL}$ of $\mathrm{NH}_{4} \mathrm{OH}(35 \% \mathrm{v} / \mathrm{v})$ drop by drop, resulting a strong blue solution with the formation of a complex $\left[\mathrm{Ni}\left(\mathrm{NH}_{3}\right)_{6}{ }_{6}^{2+}\right.$. This solution was transferred to an autoclave, coated by Teflon and heated in a furnace at $120^{\circ} \mathrm{C}$ for $12 \mathrm{~h}$. After cooling, the resulted precipitate was centrifuged and washed several times with distilled-deionized water, dried at $50^{\circ} \mathrm{C}$ for $8 \mathrm{~h}$, forming the $\left(\beta-\mathrm{Ni}(\mathrm{OH})_{2}\right)$ precipitate. $\mathrm{NiO}$ was formed after calcination at $673 \mathrm{~K}$ for $4 \mathrm{~h}$ and a heating rate of $3 \mathrm{~K} \mathrm{~min}^{-1}$.

\section{Characterizations}

The X-ray powder diffraction measurements were performed in a Rigaku Miniflex diffractometer operated at $30 \mathrm{kV}$ and $40 \mathrm{~mA}$, using the graphite monochromated $\mathrm{Cu} \mathrm{K} \alpha$ radiation. The diffractograms were recorded over $2 \theta$ values ranging from 10 to $90^{\circ}$, with a scanning rate of 2 s step $^{-1}$ and 0.02 step sizes.

Sample images were recorded in a field emission gun scanning electron microscope (FEG-SEM) (FEI Company) model QUANTA 400, equipped with an energy dispersive $\mathrm{X}$-ray spectroscopy (EDS) system without treatment. The samples were first dispersed in isopropyl alcohol, using ultrasonic bath for $10 \mathrm{~min}$, then a small amount of this solution was dropped on a copper grid and dried before analysis.

\section{Catalytic tests}

Temperature programmed surface reaction (TPSR) experiments were carried out, by using pure methane at $50 \mathrm{~cm}^{3} \mathrm{~min}^{-1}$, varying the temperature from 298 to $773 \mathrm{~K}$, at a heating rate of $10 \mathrm{~K} \mathrm{~min}^{-1}$. The masses of catalyst used were $25 \mathrm{mg}$ for the unsupported and $100 \mathrm{mg}$ for the supported catalysts, respectively. TPSR experiments were performed in a Micromeritics TPD/TPR 2900 equipment coupled to a Balzers quadrupole mass spectrometer as detector. The gases used were $\mathrm{CH}_{4}$ (99.95\% purity), He (99.995 purity).
Activity tests were conducted at atmospheric pressure in a Pyrex micro reactor of fixed bed using 100 $\mathrm{mg}$ of the supported and $25 \mathrm{mg}$ of the unsupported $\mathrm{Ni}$ catalysts, respectively. Output gases were analyzed in a gas chromatograph coupled online brand Varian, model CP-3800 GC, equipped with column CP Poraplot Q, operating in isothermal condition. He was used as carrier gas. The products were analyzed by flame ionization detector (FID) and thermal conductivity detector (TCD). Before reaction, the catalysts were pretreated with pure $\mathrm{CH}_{4}$, at $30 \mathrm{~cm}^{3} \mathrm{~min}^{-1}, 773 \mathrm{~K}$, and heating rate of $10 \mathrm{~K} \mathrm{~min}^{-1}$.

\section{Results}

Temperature programmed surface reaction (TPSR) and $\mathrm{XRD}$ analyses before and after reaction

The adsorption and decomposition mechanism of methane on metallic surfaces is an exothermic activation process of dissociative and homolytic in nature. The kinetics of $\mathrm{CH}_{4}$ adsorption on metallic surfaces has been studied in the literature by TPSR on different supported metals, films and crystallites. However, there is little about the methane decomposition on unsupported nanosized metallic crystals. Therefore, we prepared the nanosized crystallites by different methods, which were tested and characterized before and after the reaction decomposition and after exposure of the catalyst to methane for $5 \mathrm{~h}$.

The supported $25 \mathrm{NiZ}$ and unsupported NiEG catalysts

Temperature programmed surface reaction results for the supported $25 \mathrm{NiZ}$ catalyst are presented in Figure 1a, showing the methane $(\mathrm{m} / \mathrm{z}, 15)$, hydrogen $(\mathrm{m} / \mathrm{z} 2)$ and water $(\mathrm{m} / \mathrm{z}, 18)$ profiles with increasing temperature up to $773 \mathrm{~K}$ and at a heating rate of $10 \mathrm{~K} \mathrm{~min}^{-1}$. Figure $1 \mathrm{~b}$ shows the profiles of the unsupported NiEG sample.

The behavior of these samples is quite different. For the supported $25 \mathrm{NiZ}$ sample, the water profile $(\mathrm{m} / \mathrm{z}, 18)$ increases initially with time on stream but after reaching a maximum peak it decreases, indicating firstly methane decomposition and simultaneously $\mathrm{H}_{2}(\mathrm{~m} / \mathrm{z}, 2)$ consumption, which can be attributed to the reduction of $\mathrm{NiO}$ to metallic sites and water formation. In fact, methane is highly decomposed initially, decreasing then with time at lower conversion, indicating thus the partial deactivation of the catalyst, due to the carbon deposition. On the other hand, the unsupported NiEG sample showed constant profiles with time on stream after initial activation, including for water $(\mathrm{m} / \mathrm{z}, \mathrm{18})$, suggesting a slower process of $\mathrm{NiO}$ reduction during the reaction. No longer had 

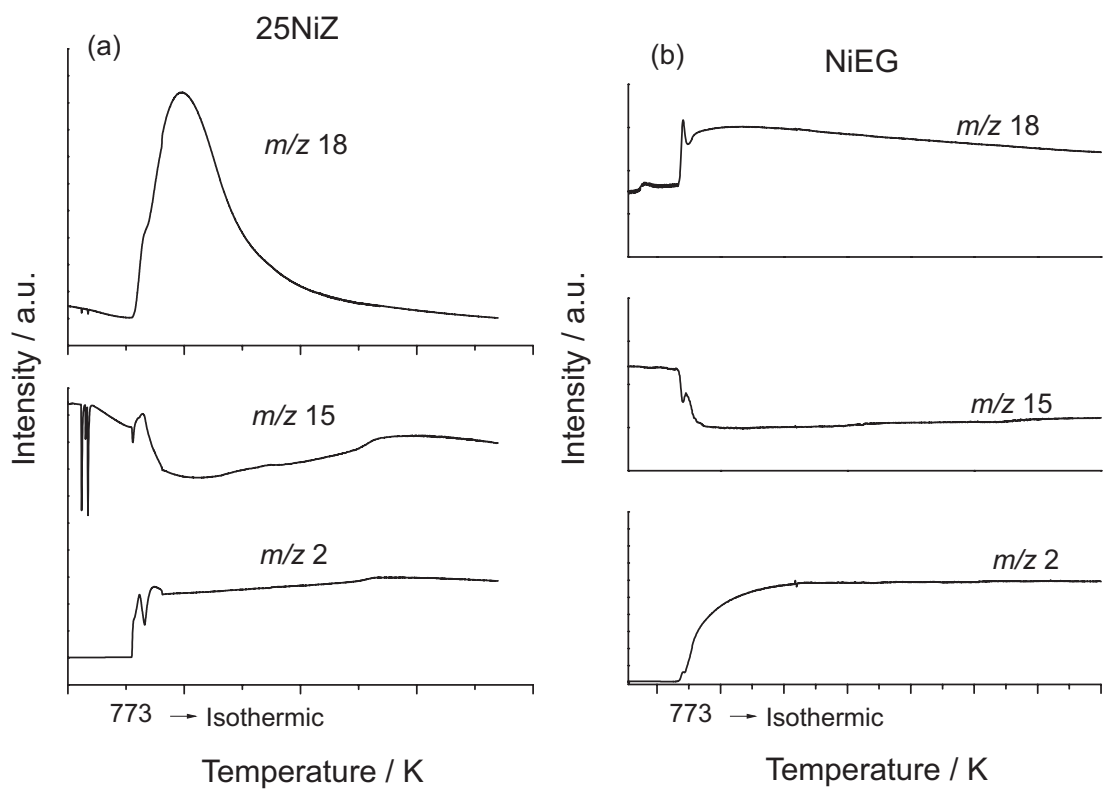

Figure 1. Temperature programmed surface reaction profiles (TPSR) of $25 \mathrm{NiZ}$ (a) and NiEG (b) catalysts.

deactivation occurred, but only decomposition of methane at higher conversions.

In fact, the diffractograms of the supported $25 \mathrm{NiZ}$ catalyst before and after reaction, which are presented in Figure 2A, evidence firstly the presence of a tetragonal phase of zirconia and before reaction only the nickel oxide. However, after reaction, it presents only metallic $\mathrm{Ni}^{0}$ cubic phase, as shown in the diffraction peaks at $44.5^{\circ}$ (111), $51.8^{\circ}(200)$ and $76.4^{\circ}(220)$. Besides, there are diffraction peaks at $26^{\circ}(002)$ and $42^{\circ}(101)$, which are assigned to the carbon phase as graphite structure.

Figure 2B displays the diffractograms of the unsupported NiEG sample before and after reaction. Before the reaction, exhibits diffraction peaks at $37.26^{\circ}(111), 43.28^{\circ}(200), 62.88^{\circ}$ (220), $75.38^{\circ}$ (311) and $79.75^{\circ}(222)$, which are assigned to $\mathrm{NiO}$ cubic phase. After reaction, exhibits diffraction peaks at $44.5^{\circ}, 51.8^{\circ}$ and $76.4^{\circ}$, which are attributed to the metallic $\mathrm{Ni}^{\circ}$, besides the peaks at $26^{\circ}(002)$ and $42^{\circ}(101)$, corresponding to a graphite structure.

\section{The unsupported NiDMG sample}

Figure 3A displays the mass spectra profiles of $\mathrm{H}_{2} \mathrm{O}$, $\mathrm{CH}_{4}$ and $\mathrm{H}_{2}$ of the NiDMG sample. Different from the previous NiEG sample, the NiDMG catalyst lost activity, since the $\mathrm{H}_{2}$ evolution and methane consumption decreased with time on stream, after initial decomposition of methane and activation of $\mathrm{NiO}$ into metallic $\mathrm{Ni}^{0}$.

Indeed, Figure 3B shows the diffractograms of the unsupported NiDMG catalyst before and after reaction at $773 \mathrm{~K}$ for $5 \mathrm{~h}$. Before the reaction, there are diffraction lines attributed to $\mathrm{NiO}$ cubic phase, beside the diffraction lines assigned to the $\mathrm{Ni}^{0}$ metallic crystalline phase.
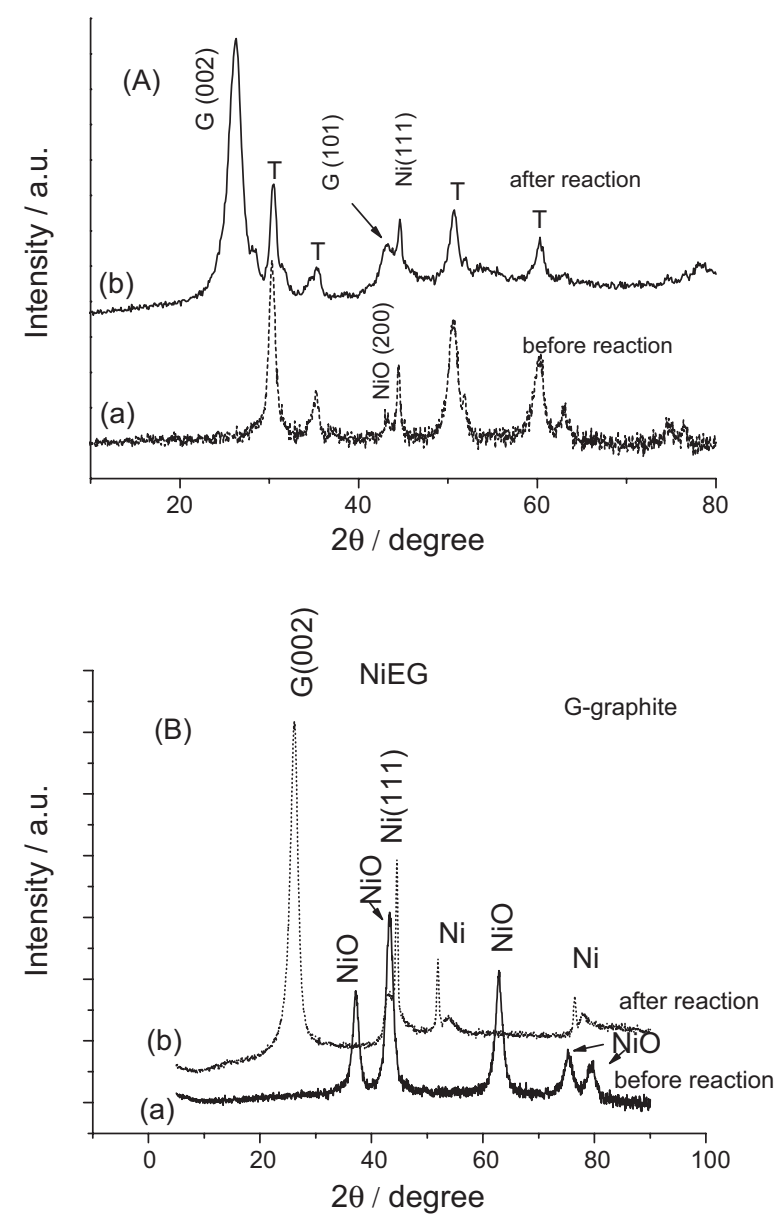

Figure 2. XRD of $25 \mathrm{NiZ}$ catalyst (A) before (a) and after (b) reaction; XRD of the NiEG catalyst (B) before (a) and after (b) reaction: G: graphite; $\mathrm{T}$ : tetragonal zirconia. 
However, after the reaction, it shows only diffraction lines corresponding to the $\mathrm{Ni}^{0}$ metallic phase and of the graphite structure. However, when compared to the previous NiEG, these graphite diffraction lines are less intense.
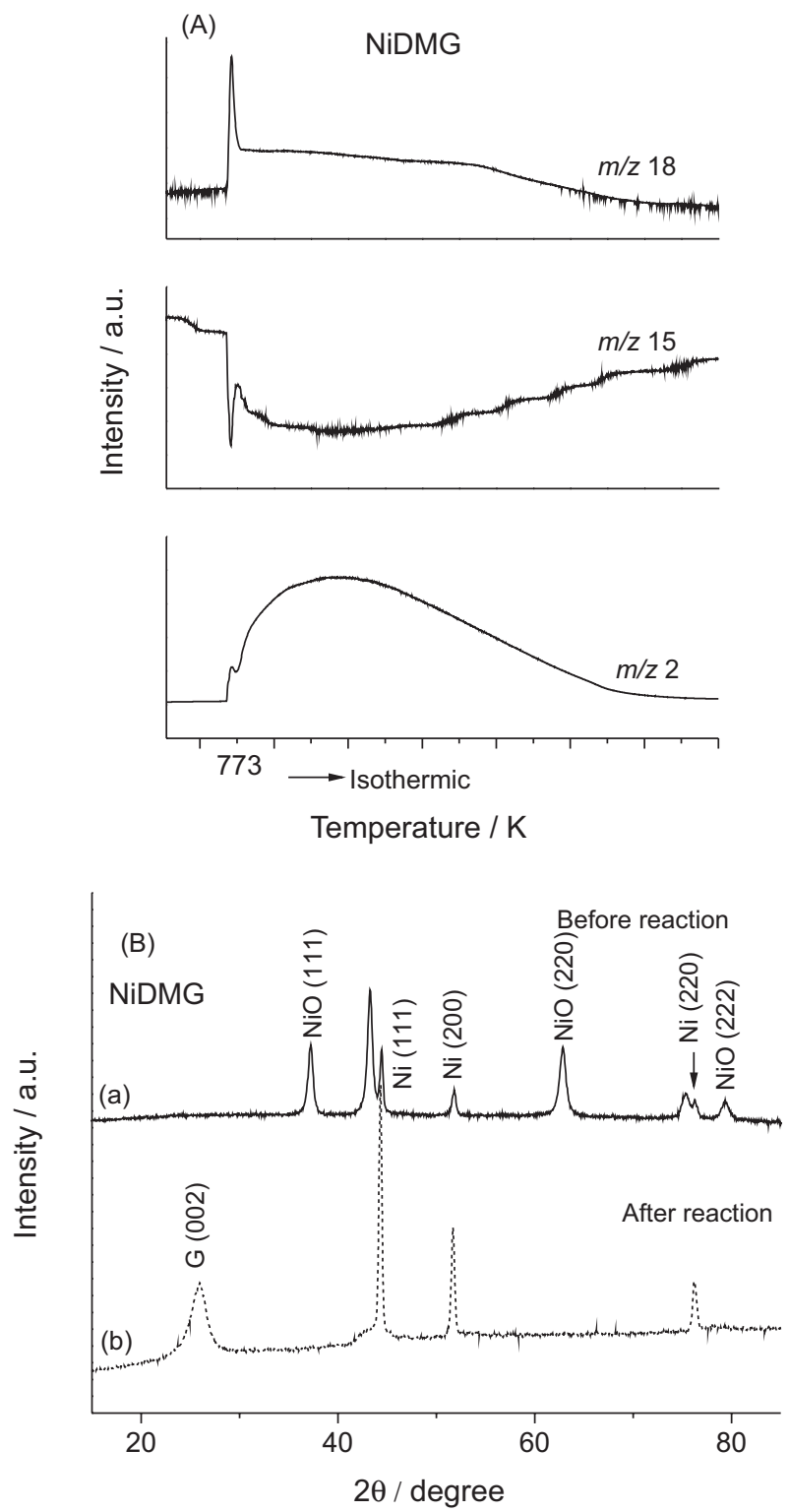

Figure 3. Temperature programmed surface reaction profiles (TPSR) of $25 \mathrm{NiDMG}$ (A); (B) XRD diffraction of the NiDMG catalyst before (a) and after (b) reaction decomposition at $773 \mathrm{~K}$.

The hydrotermal precursor (NiHT)

The unsupported NiHT was obtained after hydrotreatment and calcination of $\beta-\mathrm{Ni}(\mathrm{OH})_{2}$ precursor. $^{16}$ Figure 4A displays the profiles of methane decomposition on the NiHT with increasing temperature. Like the NiEG sample, the profiles are very similar during the reaction. After an initial activation of $\mathrm{Ni}$ species by methane, which was done during time on stream, as evidenced by the profile of water formation, methane is decomposed, with the formation $\mathrm{H}_{2}$ at a constant level.

Figure 4B displays the diffratograms of the NiHT before and after exposition to methane at $773 \mathrm{~K}$ by $5 \mathrm{~h}$. Before reaction, the diffraction pattern shows the lines corresponding to the $\mathrm{NiO}$ cubic phase. After treatment, only refraction lines corresponding to metallic $\mathrm{Ni}^{0}$ phase and graphite were observed.
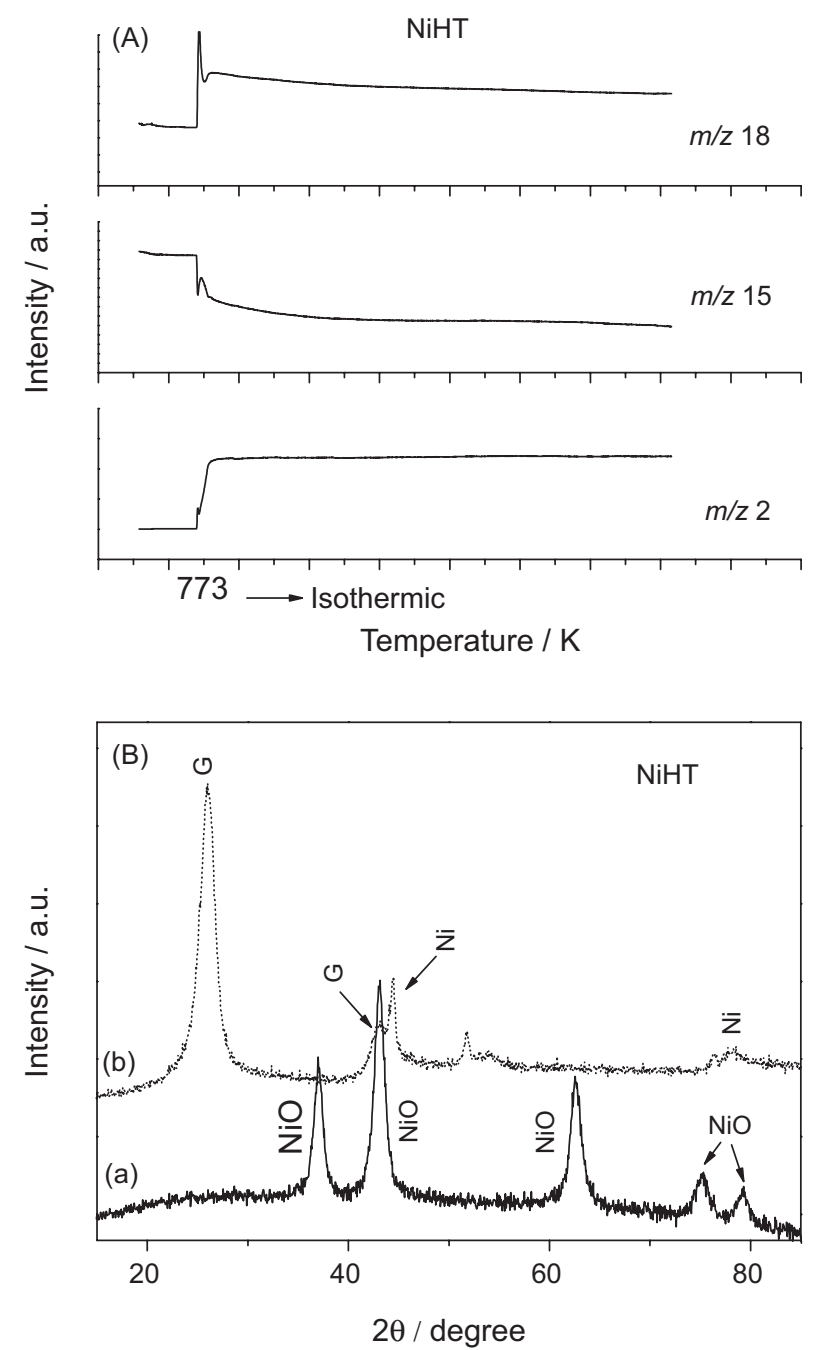

Figure 4. Profiles during $\mathrm{CH}_{4}$ decomposition with increasing temperature of NiHT (A); XRD of the NiHT sample (B): before (a) and after (b) $\mathrm{CH}_{4}$ decomposition at 773K. G: graphite.

\section{Scanning electronic microscopy (SEM-FEG)}

Figure 5 displays the scanning electronic microscopic analyses. Figure 5a shows a nanoflower like type morphology in tridimensional form of $\mathrm{NiO}$ on the NiEG sample before the reaction. This morphology was originally observed on the hydroxide before calcination and seems to be very stable after thermal pretreatment; thus, removing water did not damage the structure of the precursor. 
The structure did not collapse or fracture, which can be attributed to the excellent contact between nanoparticles with high orientation degree..$^{14}$

Figure $5 b$ shows $\mathrm{SEM}$ images of $\mathrm{NiO}$ after calcination of the NiDMG precursor, indicating the presence of bidimensional rods, which suggests made up of small particles that gather forming rods. By removing the organic molecule (DMG) during heating, the arrangement of the structure of the precursor NiDMG was not affected, and according to Gui et al..${ }^{17}$ heating probably supplies energy to maintain the $\mathrm{NiO}$ nanoparticles highly oriented in the structure.
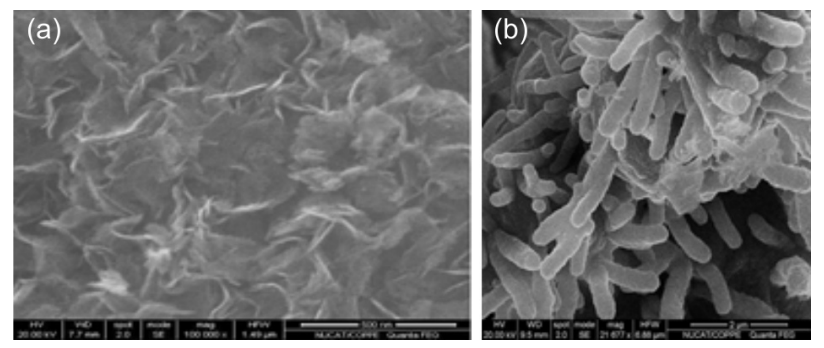

Figure 5. SEM images of the NiEG sample (a) in oxide form: 100000x; SEM images of the NiDMG sample (b) in oxide form, 20000x.

SEM images of the NiHT sample are displayed in Figure 6. The images are similar to the images of the NiEG sample, exhibiting nanosheets arranged with bends and hollow structure forming nanoflowers. However,

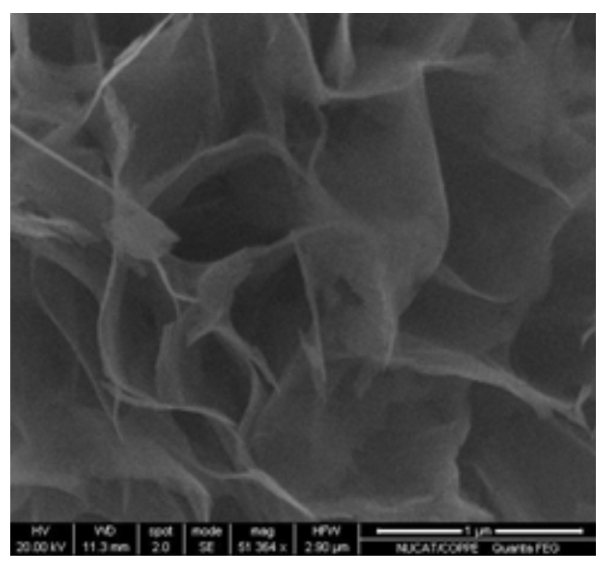

Figure 6. SEM images of the NiHT sample.
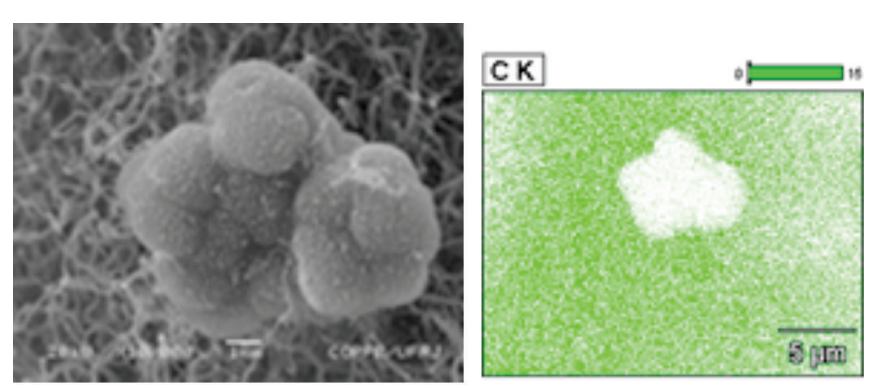

comparing the images, it seems that the NiHT sample presents structures, which are less compacted. Zhu et al. ${ }^{16}$ claims that urea and ammonia influence the formation of tridimensional structure during the preparation of the hydroxide precursor. The absence of urea results in a flaked structure and the absence of ammonia results in a structure in the form of combs.

Figure 7 displays the SEM images with the EDS analysis of $\mathrm{C}, \mathrm{Zr}$ and $\mathrm{Ni}$ of $25 \mathrm{NiZ}$ catalyst after $5 \mathrm{~h}$ of methane exposition at $773 \mathrm{~K}$. As observed by Aiello, ${ }^{8}$ on supported nickel catalysts, methane is decomposed at the interface gas-metal followed by dissolution and carbon diffusion through the metal particles. These carbons then precipitate at the interface dragging out the metallic particle of the support with the formation of carbon nanofilaments with metal particles at the tip. The EDS images show clearly the grain of zirconia free from carbon particles with Ni particles well dispersed on it as well as on carbon nanofilaments.

Figure 8 displays the SEM images of NiEG after $5 \mathrm{~h}$ of methane exposition at $773 \mathrm{~K}$. On unsupported $\mathrm{Ni}$ nanoparticles (NiEG, NiDMG and NiHT), there is formation of carbon nanofilaments, which acted as living supports taking the catalyst particles away and preventing them from sintering with adjacent particles. By this way, the metal particles are located at the tip of nanotubes.

\section{Activity tests}

Activity tests were conducted at atmospheric pressure in a Pyrex micro reactor of fixed bed using $100 \mathrm{mg}$ of the supported and $25 \mathrm{mg}$ of the unsupported $\mathrm{Ni}$ catalysts at $773 \mathrm{~K}$. Catalysts were pretreated with pure $\mathrm{CH}_{4}$ at $30 \mathrm{~cm}^{3} \mathrm{~min}^{-1}$ and $773 \mathrm{~K}$, and heating rate of $10 \mathrm{~K} \mathrm{~min}^{-1}$.

Figure 9 displays the results of the conversion of methane at $773 \mathrm{~K}$ for all catalysts. The unsupported NiEG, $\mathrm{NiHT}$ and the supported Ni catalysts (25NiZ) presented similar behavior and conversions around $9 \%$ with time on stream. However, the NiDMG catalyst presented much lower conversion, although the crystal sizes in nano size dimensions as the previous samples.

Figure 7. SEM image of $25 \mathrm{NiZ}$ with EDS analysis of $\mathrm{C}, \mathrm{Zr}$ and $\mathrm{Ni}$ after $5 \mathrm{~h}$ of methane exposition at $773 \mathrm{~K}$.
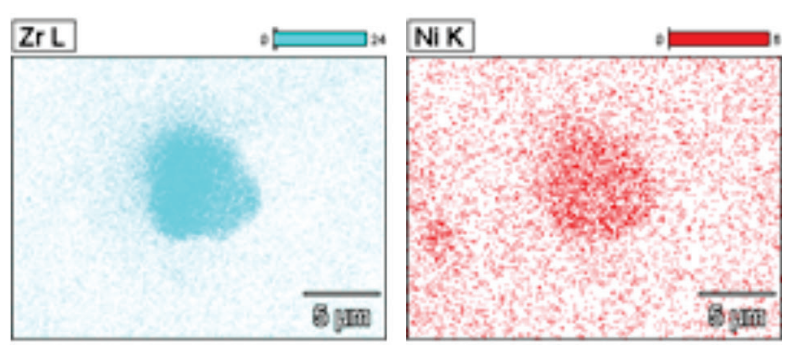


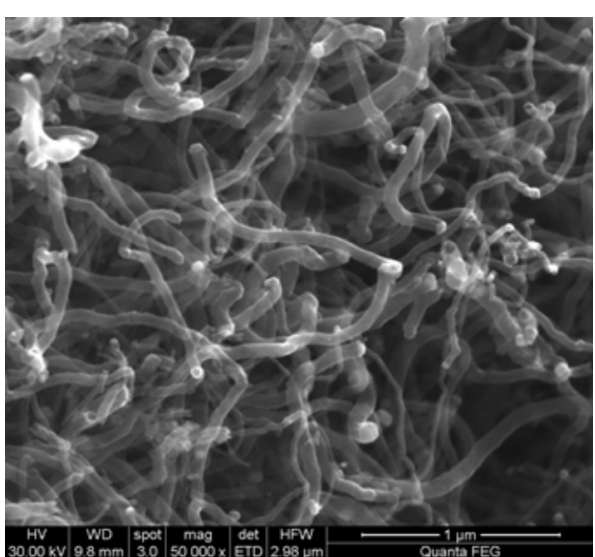

Figure 8. SEM image of NiEG after $5 \mathrm{~h}$ of methane exposition at $773 \mathrm{~K}$.

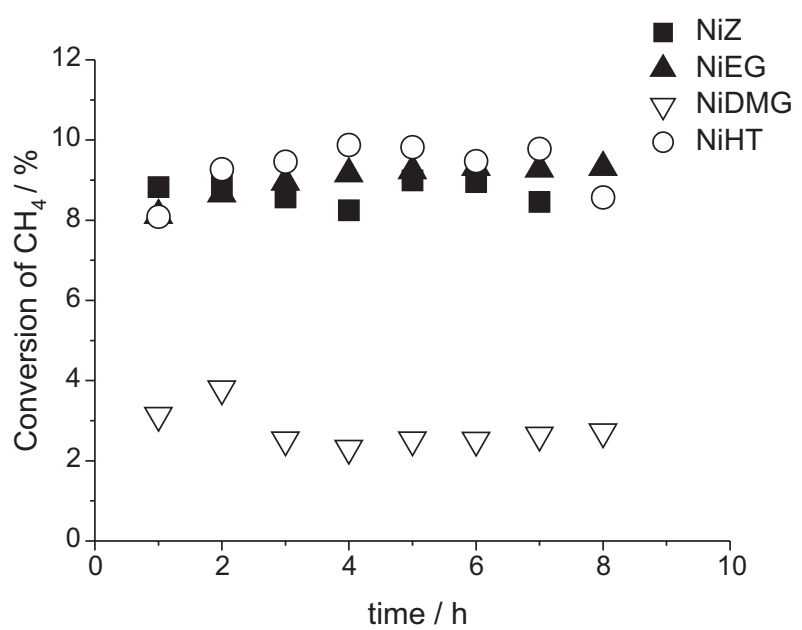

Figure 9. Conversion of methane on supported 25NiZ, and unsupported NiEG, NiDMG and NiHT catalysts.

\section{Discussion}

In et al. ${ }^{18}$ studied comparatively chemisorption and methane conversion on metallic crystallite surfaces calculating the dissociation energy of $\mathrm{C}-\mathrm{H}$ bonds of methane and showed that the main dissociated species is $\mathrm{CH}_{3}$, because it has the highest energetic barrier to split the bonding, as observed for the reaction $\mathrm{CH}_{3} \rightarrow \mathrm{CH}_{2}+\mathrm{H}^{*}$ over all surfaces. The higher the adsorption strength, the higher is the energy necessary to move surface species that migrate over the surface to meet other fragments for reacting. They concluded that ethylene should be formed through dehydrogenation of ethane and not by coupling of methane. Ciobica et al. ${ }^{19}$ calculated that on $\mathrm{Ru}(1120)$, the most stable species is $\mathrm{CH}_{2}{ }^{*}$ and that the intermediates $\mathrm{CH}_{x}$ $(1<\mathrm{x}<3)$ are more stable when adsorbed on bridged sites, while $\mathrm{C}$ species are preferentially adsorbed on top sites.

As described in our previous paper, ${ }^{9}$ the first step of the homologation reaction is the adsorption of methane, followed by the hydrogenation step. During the adsorption of methane, there are different surface carbon adspecies, which can be hydrogenated. The $\mathrm{H}_{2}$ evolution resulted from the association of hydrogen atoms provided from dissociative chemisorption of methane, as indicated by equations 2 and 3 :

$$
\begin{aligned}
& \mathrm{CH}_{4}+2^{*} \rightarrow \mathrm{CH}_{3 \mathrm{ads}}+\mathrm{H}_{\text {ads }} \\
& \mathrm{H}_{\text {ads }}+\mathrm{H}_{\text {ads }} \rightarrow \mathrm{H}_{2}+2^{*}, \text { where } * \text { represents } \mathrm{Ni}^{0} \text { sites }
\end{aligned}
$$

However, methane conversion increased besides water consumption during the reaction. These results suggest decomposition of methane (equation 2) besides methane reforming (equation 5).

$$
\begin{array}{ll}
\mathrm{CH}_{4} \leftrightarrow \mathrm{C}+2 \mathrm{H}_{2} & \Delta \mathrm{H}^{\circ}{ }_{298 \mathrm{~K}}=76 \mathrm{~kJ} \mathrm{~mol}^{-1} \\
\mathrm{CH}_{4}+\mathrm{H}_{2} \mathrm{O} \rightarrow \mathrm{CO}+3 \mathrm{H}_{2} & \Delta \mathrm{H}^{\circ}{ }_{298 \mathrm{~K}}=206.2 \mathrm{~kJ} \mathrm{~mol}^{-1}
\end{array}
$$

However, $\mathrm{CO}$ was not detected, which suggests that shift reaction may occur (equation 6), due to the presence of water, during the activation process, beside the $\mathrm{CO}$ decomposition, according to Bourduard (equation 7) and the dry reforming (equation 8).

$$
\begin{array}{ll}
\mathrm{CO}+\mathrm{H}_{2} \mathrm{O} \rightarrow \mathrm{CO}_{2}+\mathrm{H}_{2} & \Delta \mathrm{H}^{\circ}{ }_{298 \mathrm{~K}}=-41.2 \mathrm{~kJ} \mathrm{~mol}^{-1} \quad(6) \\
2 \mathrm{CO} \rightarrow \mathrm{C}+\mathrm{CO}_{2} & \Delta \mathrm{H}^{\circ}{ }_{298 \mathrm{~K}}=-172.0 \mathrm{~kJ} \mathrm{~mol}^{-1}(7) \\
\mathrm{CH}_{4}+\mathrm{CO}_{2} \rightarrow 2 \mathrm{CO}+2 \mathrm{H}_{2} & \Delta \mathrm{H}^{\circ}{ }_{298 \mathrm{~K}}=247 \mathrm{~kJ} \mathrm{~mol}^{-1}
\end{array}
$$

\section{X-ray results}

The commonly accepted model of methane decomposition and carbon growth on nickel catalysts consists of three stages: ${ }^{20,21}(i)$ methane molecules adsorb dissociatively on active surface Ni (100) and Ni (110) planes of the catalysts, which may exist as small aggregated nickel crystals, (ii) carbon diffuses into the bulk of the nickel crystallite and filaments would rapidly grow on the $\mathrm{Ni}$ (111) face of the crystallite due to the coincidental symmetry between the $\mathrm{Ni}(111)$ and the graphite (002) plane, (iii) nickel crystallites will be dragged out on the tip of the growing carbon filament. This will also prevent small crystallites contacting with neighboring particles or sintering into bigger ones.

To maintain the continuous growth of carbon nanofilaments or nanotubes, the balance between the methane decomposition rate, carbon diffusion rate and the precipitation rate can be achieved by using appropriate catalyst particle sizes. The disequilibrium occurs when the dissociation rate is much faster than the carbon diffusion rate and subsequently carbon layers will be formed on the active surfaces of the catalysts, resulting in the so-called deactivation process. ${ }^{22}$ The initial carbon nanofilaments act as transporting agent and support to take individual particles 
away, and prevent sintering with adjacent particles of the catalyst, as displayed in Figures 7 and 8 for $25 \mathrm{NiZ}$ and NiEG catalysts. Other factors influencing the feasibility of carbon filament formation include the particle size and the surface area. Smaller particle sizes and larger surface areas (more porous structure) increase the probability for methane molecules to reach the active surface and to draw the nickel crystallites away and be supported on the tip of carbon nanofibers, thus preventing them from sintering into bigger crystals. It was interesting to note that the active $\mathrm{Ni}$ particles during the reaction were usually on the tip of one carbon nanofiber only. However, Wang et al., ${ }^{23}$ upon closer inspection of deactivated unsupported Ni catalyst, found that two Ni particles collided and coalesced together with two carbon nanofibers connecting them. In fact, the micrographs of the totally deactivated $\mathrm{Ni}$ catalysts suggest that the collisions between two Ni catalyst particles or between Ni particles and carbon nanofibers might also be a reason contributing to catalyst deactivation.

The crystallite sizes of the nano structured catalyst before the reaction were calculated according to Sherrer's equation and the results are presented in Table 1. As seen, the crystallite sizes changed from $6 \mathrm{~nm}$ to $27 \mathrm{~nm}$, and depend on the preparation method. The supported $25 \mathrm{NiZ}$ catalyst presented bigger crystallites $(27 \mathrm{~nm})$, while the unsupported NiEG the lowest value $(6 \mathrm{~nm})$. These values are in the range of nanosized crystallites.

Tabel 1. Crystallite sizes of $\mathrm{NiO}$ of different precursors before reaction, reaction rates of the methane conversion and carbon formed during time on stream

\begin{tabular}{lccc}
\hline Catalyst & $\begin{array}{c}\text { Crystal size / } \\
\mathrm{nm}\end{array}$ & $\begin{array}{c}\text { Rate } \times 10^{5} / \\
{\left[\mathrm{mols}\left(\mathrm{g}_{\mathrm{Ni}} \cdot \mathrm{s}\right)^{-1}\right]}\end{array}$ & $\begin{array}{c}\text { Carbon / } \\
\mathrm{g}\end{array}$ \\
\hline NiEG & 6 & 7.14 & 0.935 \\
NiDMG & 15 & 2.68 & 0.13 \\
NiHT & 8.4 & 7.14 & 0.745 \\
$5 \mathrm{NiZ}$ & 27 & 8.04 & 0.835 \\
\hline
\end{tabular}

In our previous paper, ${ }^{17}$ we prepared nickel nanoparticles for the non-oxidative methane activation. A nickel acetate solution was impregnated on silica support and then reduced with $\mathrm{NaBH}_{4}\left(\mathrm{NiB} / \mathrm{SiO}_{2}\right)$ exhibiting only metallic $\mathrm{Ni}^{0}$ particles of the order of $15 \mathrm{~nm}$. Part of this solid was then oxidized under mild conditions, where $\mathrm{Ni}$ ions were re-structured and redistributed as a $\mathrm{Ni}-\mathrm{Ox} / \mathrm{SiO} \mathrm{O}_{2}$ oxide solid that, after reduction with hydrogen, favored the formation of smaller $\mathrm{Ni}^{0}$ particles of the order of $3.5 \mathrm{~nm}$. Comparing the results, one can conclude that crystallite sizes of the unsupported NiEG, which was prepared by precipitation of nickel hydroxide with sodium carbonate precursor salts dissolved in ethylene glycol ${ }^{14}$ (NiEG), are comparable to the method prepared by impregnation of a nickel acetate ${ }^{17}$ in contrast to the $25 \mathrm{NiZ}$ supported sample, which presented crystallite sizes 4 times bigger than the unsupported NiEG.

\section{Activity}

The reaction rates are presented in Table 1 for different catalysts. The rates of the $\mathrm{NiO}$ on the NiEG and NiHT precursors are similar and approximately equal to the reaction rate of the supported $25 \mathrm{NiZ}$ sample $\left[8.04 \times 10^{-5} \mathrm{mols}\left(\mathrm{g}_{\mathrm{NiO}} \mathrm{s}\right)^{-1}\right]$, used as reference, but three times more active than the NiDMG sample $\left[2.68 \times 10^{-5} \mathrm{mols}\left(\mathrm{g}_{\mathrm{NiO}} \mathrm{s}\right)^{-1}\right]$. In fact, the activity seems to depend on the morphology. In particular, it suggests that the nanoflower like type NiEG exposes nanosized $\mathrm{NiO}$ crystallites for the methane decomposition or dissociation, which increases the activity. On the other hand, the nanorod shape crystallites, like NiDMG precursor, are less active and probably less stable.

The results indicate that these catalysts are active for the dissociation or decomposition of methane and for the formation of carbon nanospecies species of high reactivity at the surface. Quantitatively, there are significant differences between the different samples, the supported $25 \mathrm{NiZ}$ and the unsupported NiEG, NiHT and NiDMG samples, where the first three exhibited three times more adsorption capacity than the last one. Indeed, the metal oxide crystal sizes of the NiEG and NiHT are approximately 2 times lower than of NiDMG precursor, with exception of the supported $25 \mathrm{NiZ}$ catalyst (Table 1 ). In fact, Table 1 presents the carbon formation of the different samples and shows that the amount of carbon formation is related to the activity of the different $\mathrm{NiO}$ morphologies. In our previous study, ${ }^{4}$ we observed that although the particle sizes of $\mathrm{NiB} / \mathrm{SiO}_{2}$ and $\mathrm{Ni}-\mathrm{Ox} / \mathrm{SiO}_{2}$ differ by a factor of 5 , the activity at $773 \mathrm{~K}$ or adsorption capacity of the $\mathrm{Ni}-\mathrm{Ox} / \mathrm{SiO}_{2}$ catalyst was three times more active than $\mathrm{NiB} / \mathrm{SiO}_{2}$. The adsorption capacity is attributed to the metallic nanostructured particles. Therefore, the results suggest that the structure of the metal oxide and the morphology in particular, affect the methane dissociation.

Koerts $^{24}$ observed and classified the surface carbon species as $\mathrm{C}_{\alpha}, \mathrm{C}_{\beta}$ and $\mathrm{C}_{\gamma}$. The most reactive is the carbide $\mathrm{C}_{\alpha}$ type, followed by the less active $\mathrm{C}_{\beta}$ carbon, which is amorphous. The $\mathrm{C}_{\gamma}$ or graphitic carbon is the less active. According to authors, the $\mathrm{C}_{\alpha}$ carbon species are formed on low surface coverages. Winslow et al. ${ }^{25}$ and Duncan ${ }^{26}$ indicated that methane is initially dissociated in $\mathrm{C}_{\alpha}$ carbon adsorbed species, which can be transformed immediately to $C_{\beta}$, both phases in dynamic equilibrium. However, the $\mathrm{C}_{\beta}$ carbon species can be slowly transformed by aging 
into irreversible $\mathrm{C}_{\gamma}$ species, at rates depending on the temperature and structure of the catalyst.

The dissociative adsorption of methane on Ni catalysts has been studied by different authors, showing that the estimated value of the energetic barrier of methane dissociation on $\mathrm{Ni}(100)$ crystal surface faces were $0.28 \mathrm{eV}^{27}$ and $0.54 \mathrm{eV}^{28}$ and for $\mathrm{Ni}$ (111) crystal surface $0.77 \mathrm{eV}^{29}$ Theoretical calculations indicated energetic barriers in the range of $0.69 \pm 0.04 \mathrm{eV}$ for methane dissociation on Ni (100) surfaces. ${ }^{30}$ In fact, calculations ${ }^{31}$ by density functional theory (DFT) estimated energy value of $0.60 \mathrm{eV}$ on $\mathrm{Ni}$ (100) surface; however, the presence of oxygen inhibits the methane dissociation, which is attributed to the decreasing interaction between $\mathrm{CH}_{3}$ and $\mathrm{H}$ atoms with the substrate. Therefore, to increase the exposition at the surface of the $\mathrm{Ni}(100)$ face, it is necessary to change their morphology. In fact, it suggests that nanostructures of nanoflowers like type may address the specific topology.

\section{Conclusions}

The NiO catalysts prepared using different methods for controlling the particle sizes with different organic precursors and $\mathrm{Ni}\left(\mathrm{NO}_{3}\right)_{2} \cdot 6 \mathrm{H}_{2} \mathrm{O}$ as source of $\mathrm{Ni}$, were active for methane activation with $\mathrm{H}_{2}$ and carbon nanotubes production. The initial carbon nanotubes acted as transporting agents and supports to take individual catalyst particles away and prevent them from sintering with adjacent particles. The results of this work indicate that there is a strong dependence of crystallite sizes and, in particular of the morphology, with the activation of methane and their stability. Crystallites of the order of magnitude of nanostructure favor the dissociation of methane and inhibit aggregation and formation of bigger particles that conducts to deactivation. The NiO of the NiEG and NiHT precursor presented crystallite sizes of the order of 6 and $8 \mathrm{~nm}$, respectively, while the $\mathrm{NiO}$ of NiDMG precursor presented crystallite sizes of the order of $15 \mathrm{~nm}$.

The activities of the NiO on the NiEG and NiHT precursors are similar and approximately equal to the activity of the $25 \mathrm{NiZ}$ supported sample and three times more active than the NiDMG precursor. As a matter of fact, it seems that the morphology and crystallite sizes of NiDMG catalyst leads methane dissociation rate much faster than the carbon diffusion rate and subsequently carbon layers of graphite will be formed on the active surfaces of the catalysts, resulting in the so-called deactivation process. Carbon nanofibers can only be produced when the balance between methane dissociation rate and carbon diffusion rate is maintained. In fact, the activity and the nano structured crystallites sizes depend on the morphology, which suggests that the nanoflower like type beside achieves the proper carbon diffusion rate and the precipitation rate, increases the exposing $\mathrm{Ni}(100)$ crystal surface for the methane decomposition or dissociation. Also, its structure stability can be attributed to the excellent contact between nanoparticles with high orientation degree.

\section{Acknowledgments}

Sylvia Moya, Maria Auxiliadora S. Baldanza, and the support of FINEP, CAPES and CNPq.

\section{References}

1. Martins, R. L.; Baldanza, M. A. S.; Souza, M. M. V. M.; Schmal, M.; Appl. Catal., A 2007, 318, 207.

2. Moya, S. F.; Martins, R. L.; Ota, A.; Kunkes, E. L.; Behrens, M.; Schmal, M.; Appl. Catal., A 2012, 411-412, 105.

3. Ota, A.; Kunkes, E. L.; Krohnert, J.; Schmal, M.; Behrens, M.; Appl. Catal., A 2013, 452, 203.

4. Moya, S. F.; Martins, R. L.; Schmal, M.; Appl. Catal., A 2011, 396, 159.

5. Muradov, N. Z.; Energy Fuels 1998, 12, 41.

6. Poirier, M. G.; Sapundzhiev, C.; Int. J. Hydrogen Energy 1997, 22, 429.

7. Choudhary, T. V.; Goodman, D. W.; Catal. Lett. 1999, 59, 93.

8. Aiello, R.; Fiscus, J. E.; zur Loye, H-C.; Amiridis, M. D.; Appl. Catal., A 2000, 192, 227.

9. Alberton, A. L.; Souza, M. M. V. M.; Schmal, M.; Appl. Catal., B 2011, 103(3-4), 326.

10. Martins, R. L.; Baldanza, M. A. S.; Alberton, A. L.; Vasconcelos, S. M.; Schmal, M.; Appl. Catal., B 2011, 103, 326.

11. Bell, A. T.; Science 2003, 299, 1688.

12. Grass, M. E.; Yue, Y.; Habas, S. E.; Rioux, R. M.; Teall, C. I.; Yang, P.; Somorjai, G. A.; J. Phys. Chem. C 2008, 112, 4797.

13. Albiter, M. A.; Zaera, F.; Appl. Catal., A 2011, 391, 386.

14. Li, Y.; Zhang, B.; Xie, X.; Liu, J.; Xu, Y.; Shen, W.; J. Catal. 2006, 238, 412.

15. Ni, X.; Zhao, Q.; Zhou, F.; Zheng, H.; Cheng, J.; Li, B.; J. Cryst. Growth 2006, 289, 299.

16. Zhu, L. P.; Liao, G. H.; Yang, Y.; Xiao, H. M.; Wang, J. F.; Fu, S. Y.; Nanoscale Res. Lett. 2009, 4, 550.

17. Gui, Z.; Liv, J.; Wang, Z.; Song, L.; Hu, Y.; Fan, W.; Chen, D.; J. Phys. Chem. B 2005, 109, 1113.

18. In, Y. Z.; Sun, J.; Yi, J.; Lin, J. D.; Chen, H. B.; Liao, D. W.; J. Mol. Struct. 2002, 587, 63.

19. Ciobica, I. M.; van Santen, R. A.; J. Phys. Chem. B 2002, 106, 6200.

20. Li, Y. D.; Li, D. X.; Wang, G. W.; Catal. Today 2011, 162, 1.

21. Dupuis, A. C.; Prog. Mater. Sci. 2005, 50, 929.

22. Yang, R. T.; Chen, J. P.; J. Catal. 1989, 115, 52. 
23. Wang, H. Y.; Lua, A. C.; J. Phys. Chem. 2012, 116, 26765.

24. Koerts, T.; Deelen, M. J. A.; van Santen, R. A.; J. Catal. 1992, $138,101$.

25. Winslow, P.; Bell, A. T.; J. Catal. 1985, 94, 385.

26. Duncan, T. M.; Winslow, P.; Bell, A. T.; J. Catal. 1985, 93, 1.

27. Beebe Jr, T. P.; Goodman, D. W.; Kay, B. D.; Yates, J. T.; J. Chem. Phys. 1987, 87, 2305.

28. Chorkendorff, I.; Alstrup, I.; Ullmann, S.; Surf. Sci. 1990, 227, 291.
29. Egeberg, R. C.; Ullmann, S.; Astrup, I.; Mullins, C. B.; Chorkendorff, I.; Surf. Sci. 2002, 497, 183.

30. Swang, O.; Faegri Jr., K.; Gropen, O.; Wahlgren, U.; Siegbahn, P.; Chem. Phys. 1991, 156, 379.

31. Xing, B.; Pang, X-Y.; Wang, G-C.; Shang, Z-F.; J. Mol. Catal. A: Chem. 2010, 315, 187.

Submitted on: July 17, 2014 Published online: November 11, 2014 